\title{
Exploring the Intention to Continuance of Learning Programming at Elementary School of Rural Area by the mBot Robot
}

\author{
Yung-Hsin Cheng \\ Department of Information Management, National Yunlin University of Science and Technology, \\ 123 University Road, Section 3, Douliou, Yunlin 64002, Taiwan, R.O.C. \\ Jia-Ming Hsiao \\ Bachelor Program in Interdisciplinary Studies, National Yunlin University of Science and Technology, \\ 123 University Road, Section 3, Douliou, Yunlin 64002, Taiwan, R.O.C. \\ E-mail: cindy6092624@gmail.com,hsiaojm@yuntech.edu.tw \\ https://www.yuntech.edu.tw
}

\begin{abstract}
Since Curriculum Guidelines of 12-Year Basic Education implemented by the Ministry of Education in 2018, the program learning courses have been added to junior high school education. However, there are no programming course in the elementary school. This study is proposed to explore the continuity and intentions of the rural area students in the programming course with mBot robot and mBlock programming tool through the Post-Acceptance Model of IS Continuance. It is indicated that enlightenment education of computational thinking should be implemented during the elementary school by means of graphical programming software and robot practice. Through the graphical software and teaching robots, we can cultivate problem solving skills for students' logic, creative thinking and communication, as well as through the task-guided way to train the students' concentration and perseverance.
\end{abstract}

Keywords: Rural Education, Robot programming, Makeblock mBot, Post-Acceptance Model of IS Continuance.

\section{Introduction}

In 2018, the Curriculum Guidelines of 12-Year Basic Education had been implemented by the Ministry of Education, Taiwan. One of the major changes is that curriculum development in the field of technology in junior and senior high school should be compatible with information technology and life technology. The programing language courses have been added to junior high school education. However, the programming course is not essential but implemented as a flexible curriculum in the elementary school. It is indicated that enlightenment education of computational thinking should be implemented during the elementary school by means of graphical programming software and robot practice. Through the graphical software and education robots, we can cultivate problem solving skills for students' logic, creative thinking and communication, as well as through the task-guided way to train the students' concentration and perseverance. On the other hand, it is also observed that there exists digital divide in education between urban and rural schools. The digital divide can be reduced by the skill training of software, programming and problem solving. In the mean time, many volunteers provide learning activities of programing and robot education for rural school to assist in teaching and learning in Taiwan.

mBot is an education robot for beginners, that was announced by Makeblock Co., Ltd in 2015. In Taiwan, it 
is often used in elementary and junior high school to develop the students' computational thinking and programming skills. The programming tool is mblock which is a block-based and code-based programming software developed from Scratch. The mBot robot course is aimed on the Grade 3 to 6 students of elementary students. There are four topics that include logical thinking, sensors, differential driven wheel robot and project practice to cultivate problem solving skills for students' logic, creative thinking and communication, as well as through the task-guided way to train the students' concentration and perseverance.

Expectation-Confirmation Theory was proposed by Oliver ${ }^{1}$. The sustainability theory in the IS research field draws on Expectation-Confirmation Theory in consumer behavior. However, Bhattacherjee ${ }^{2}$ believes that the Expectation-Confirmation Theory is controversial and unreasonable in some aspects. He proposed postacceptance model of IS continuance by the concept that continuance usage intention of information system will be influenced by usage satisfaction and perceived ease of use. Many scholars conduct related research based on the post-acceptance model of IS continuance, but there are not many related researches on education. Based on the post-acceptance model of IS continuance, the students' perceived usefulness of the curriculum can be used as a reference benchmark for confirmation and judgment, which will positively affect their satisfaction with the curriculum $^{3}$.

This study is proposed to explore the continuity and intentions of the rural area students in the programming course with mBot robot and mBlock programming tool through the post-acceptance model of IS continuance. The purpose is to explore students' satisfaction with programming courses, and to understand whether it can stimulate students' motivation to continue participating advanced programming courses.

\section{Research structure}

This study is based on the Post-Acceptance Model of IS Continuance, as shown in Fig. 1. It is implemented by the following steps:

(i) Teaching and learning mBot,

(ii) Example exercise,

(iii) Group project, (iv) Questionnaire collecting and analysis.

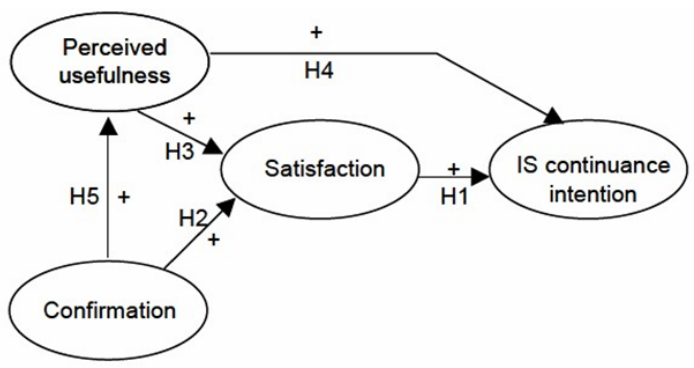

Fig. 1 Post-Acceptance Model of IS Continuance ${ }^{2}$

\subsection{Teaching and learning $\mathrm{mBot}$}

There are four rural elementary schools participated in this study. The course is implemented in the formal course in two schools, and in the student club in the other two schools. There are 85 students participated in the course. The students are divided into groups in which there two members each. Group members are encouraged to show their team-work spirit and knowledge sharing.

\subsection{Example exercise}

Each lesson is arranged to focus on one theme, e.g., motor control, sensor application, etc. A short example is given in class, and the students are asked to test and practice an exercise. Both mechanical and programming discussion are applied to each group. The subject of exercise may be from the missions of MakeX robot competition.

\subsection{Group project}

In the last two or three lessons of the semester, a group project is assigned to each group. The project assigned to Grade 3 and 4 students is RoboRAVE a-maze-ing problem, and Grade 5 and 6 students are assigned to solve the line-following and object avoiding problems. 


\subsection{Development of research model and propositions}

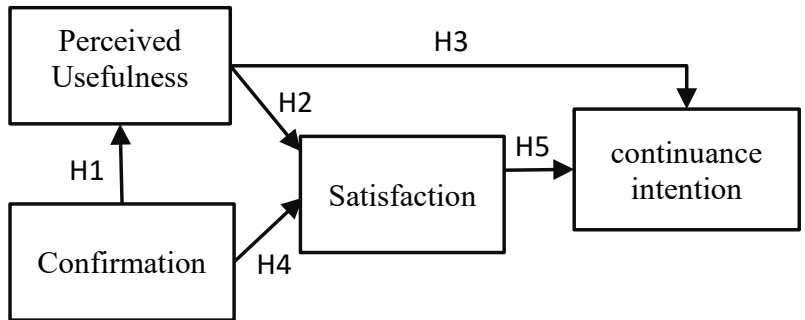

Fig. 2 research framework

Based on the Post-Acceptance Model of IS Continuance, the research framework is shown as Fig. 2. There are five hypotheses made in this study:

H1: Users' confirmation has the significant influence on satisfaction.

H2: Users' perceived usefulness has the significant influence on satisfaction.

H3: Users' perceived usefulness has the significant influence on continuance intention of programming course.

H4: Users' confirmation of programming course has the significant influence on satisfaction.

H5: Users' satisfaction of programming course has the significant influence on continuance intention of programming course.

The four factors of research framework are defined as followings:

- $\quad$ perceived usefulness: Students subjectively feel that programming courses are helpful for learning.

- confirmation: After students experience the programming course, their before and after psychological expectations of the experience are the same.

- satisfaction: How the students feel about the programming course after the experience.

- continuance intention: Students are willing to continue learning programming courses in the future.

\section{Main results}

After the programming course, a questionnaire is issued to students. There received 68 questionnaire samples, and 65 samples are valid, the other 3 samples are invalid. The students' basic personal information are listed in Table 1.
Table 1 Students' basic personal information

\begin{tabular}{|c|c|c|c|}
\hline \multicolumn{2}{|c|}{ Basic personal information } & Count & Percentage $(\%)$ \\
\hline \multirow{2}{*}{ Gender } & Male & 43 & 66.2 \\
\hline & Female & 22 & 33.8 \\
\hline \multirow{4}{*}{ Age } & $<=10$ & 37 & 56.9 \\
\hline & 11 & 15 & 23.1 \\
\hline & 12 & 8 & 12.3 \\
\hline & $>12$ & 5 & 7.7 \\
\hline \multirow{4}{*}{ Grade } & 3 & 14 & 21.5 \\
\hline & 4 & 30 & 46.2 \\
\hline & 5 & 8 & 12.3 \\
\hline & 6 & 13 & 20.0 \\
\hline \multirow{4}{*}{$\begin{array}{l}\text { How long to } \\
\text { learn mBot? }\end{array}$} & 1 semester & 57 & 87.7 \\
\hline & 2 semesters & 7 & 10.8 \\
\hline & 3 semesters & 0 & 0 \\
\hline & 4 semesters & 1 & 1.5 \\
\hline \multirow{2}{*}{$\begin{array}{c}\text { Experience } \\
\text { coding? }\end{array}$} & Yes & 47 & 72.3 \\
\hline & No & 18 & 27.7 \\
\hline \multirow{2}{*}{$\begin{array}{c}\text { Interested in } \\
\text { coding before } \\
\text { learning mBot? }\end{array}$} & Yes & 55 & 84.6 \\
\hline & No & 10 & 15.4 \\
\hline \multirow{2}{*}{$\begin{array}{l}\text { Using computer } \\
\text { or tablet after } \\
\text { school? }\end{array}$} & Yes & 60 & 92.3 \\
\hline & No & 5 & 7.7 \\
\hline \multirow{5}{*}{$\begin{array}{l}\text { Average time of } \\
\text { using computer } \\
\text { or tablet every } \\
\text { day }\end{array}$} & 0 & 5 & 7.7 \\
\hline & $<1 \mathrm{Hr}$ & 27 & 41.5 \\
\hline & $1 \sim 2 \mathrm{Hr}$ & 14 & 21.5 \\
\hline & $2 \sim 3 \mathrm{Hr}$ & 7 & 10.8 \\
\hline & $>3 \mathrm{Hr}$ & 12 & 18.5 \\
\hline
\end{tabular}

After the data analysis, the result of five hypotheses is shown as Table 2. It is shown that hypotheses H1, H2, $\mathrm{H} 4$ and $\mathrm{H} 5$ have significant influence, and $\mathrm{H} 3$ does not.

Table 2 Data analysis result

\begin{tabular}{cccc}
\hline Hypothesis & Path coefficient $(\beta)$ & t-value & p-value \\
\hline H1 & 0.691 & 6.335 & $<0.001^{* * *}$ \\
H2 & 0.410 & 3.273 & $<0.001^{* * *}$ \\
H3 & -0.005 & 0.053 & 0.958 \\
H4 & 0.518 & 4.769 & $<0.001^{* * *}$ \\
H5 & 0.925 & 11.782 & $<0.001^{* * *}$
\end{tabular}

\section{Conclusions}

From Table 1, it is shown that there are $72.3 \%$ students experienced programming course, $84.6 \%$ students are interested in coding before learning $\mathrm{mBot}$, and $87.7 \%$ students have one-semester experience of learning mBot. 
This research believes that after experiencing the mBot programming course, students have more willing and motivation to learn to code, and are willing to learn about other programming after school.

We observed that most of the students are a little afraid of learning the new programming course before the course. For the brand-new programming course, the original expectation was low. After experiencing the mBot programming course, through the combined teaching of mBlock and mBot robot, the expectation after the course was greater than expected. With the mBot robot programming course, students can learn and understand programming applications faster with fun, so as to be satisfied with the mBot robot programming course. With respect to the degree of confirmation of students in the mBot program course, it is indicated that the higher their degree of confirmation, the higher their satisfaction. It is confirmed that the satisfaction of $\mathrm{mBot}$ programming courses will positively affect the students' intention to continue participating programming courses. It is observed in this research, students' satisfaction with programming courses makes them willing to spend more time on learning programming, and students will be more willing to actively learn advanced programming courses.

However, students' enthusiasm may decay along with time passed. It could result from that students do not know why they should learn robot programming. Teachers should link the robot programming course to real life applications or examples. With the linkage, students are guided to build and program useful robots to solve problems. It is also important to encourage students to share their ideas of building robots, and then to maintain students' enthusiasm for learning programming and robot building.

\section{References}

1. Oliver, R. L. and Richard, L., A cognitive model for the antecedents and consequences of satisfaction decision, Journal of Marketing Research, 17(4), 1980, pp. 460-469.

2. Bhattacherjee, A., Understanding information systems continuance: An expectation-confirmation model, MIS Quarterly, 25(3), 2001, pp. 351-370.
3. Lee, M.-C., Explaining and predicting users' continuance intention toward e-learning: An extension of the expectation-confirmation model, Computers \& Education, 54(2), 2010, pp. 506-516.
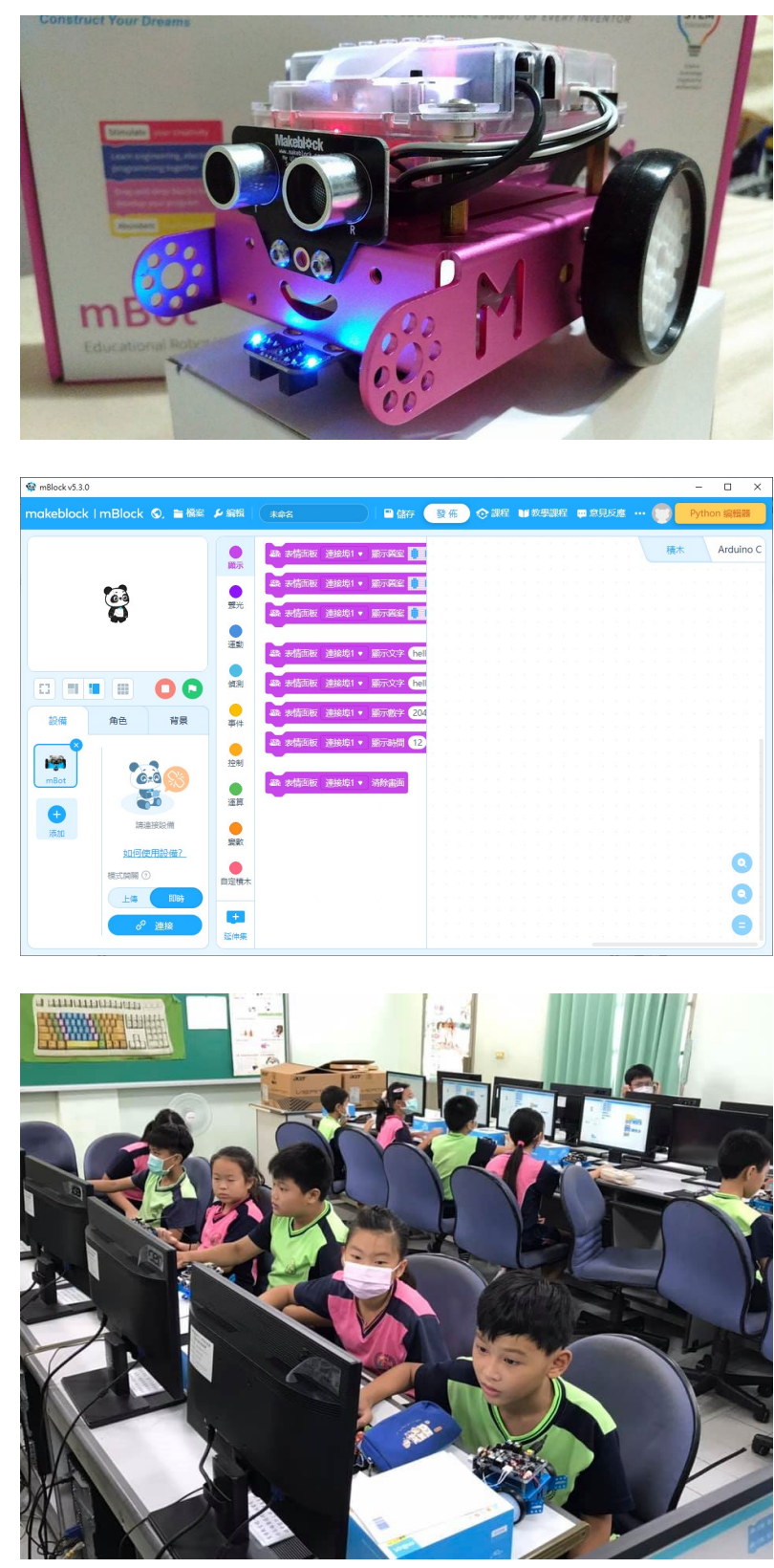